\title{
Understanding the importance of graduate admissions criteria according to prospective graduate students
}

\author{
Deepa Chari ${ }^{1}$ and Geoff Potvin ${ }^{1,2}$ \\ ${ }^{1}$ STEM Transformation Institute, Florida International University, Miami, Florida 33199, USA \\ ${ }^{2}$ Department of Physics, Florida International University, Miami, Florida 33199, USA
}

(Received 16 April 2019; published 24 September 2019)

\begin{abstract}
Understanding perceptions of graduate admissions from multiple stakeholders can cultivate an improved understanding about the process of graduate induction, the role that admissions plays in restricting diversity in physics, and contribute to more informed practices for all involved. Prior studies in graduate admissions have reported on how certain admission criteria weigh in the consideration of applicants primarily from faculty perspectives. Motivated by the concept of multivocal knowledge, in this article, we report on prospective students' perspectives of the importance of the same admission criteria—a stakeholder group that is critical but underempowered in the admissions process. We identify a substantial agreement between students and faculty regarding the importance of recommendation letters, undergraduate math or physics GPA, and standardized exam scores (GRE). On the other hand, students rated several criteria, including personal statements, prior research experiences, publications, and familiarity with department as significantly more important than did faculty. A perceived "overimportance" of criteria may be detrimental to students' admissions-related decision making and reduce their chances of success, so these results emphasize the importance of taking students' perspectives into account in the admissions process.
\end{abstract}

DOI: 10.1103/PhysRevPhysEducRes.15.023101

\section{INTRODUCTION}

To address the lack of diversity in graduate physics nationwide, many physics departments are becoming increasingly interested in recruiting a more diverse student population [1,2]. In conjunction with the American Physical Society Bridge Program (APS-BP), many issues associated with graduate diversification have been studied, from an examination of current admission practices [3,4], an exploration of faculty mindset and its effects on recruitment [5], identification of programmatic structures and practices that support graduate students' entry $[1,6]$ and enculturation [7]. Much of this work, including that of the current authors, has previously focused on faculty or departments to inform about institutional decision making and values $[8,9]$. Students are often (implicitly) framed as being at the receiving end of these practices, which has left the role that students play as active stakeholders in these systems underemphasized. Moreover, little is known about how graduate departments can apply knowledge gained from multiple stakeholders' perspectives.

Published by the American Physical Society under the terms of the Creative Commons Attribution 4.0 International license. Further distribution of this work must maintain attribution to the author(s) and the published article's title, journal citation, and DOI.
A critical perspective on the graduate education process (admissions complexity, research and course taking, career prospects and future success, etc.) is that of prospective students (that is, undergraduate students who may be considering graduate school). These perceptions shape their decisions about which school to apply to, what efforts to make, and influence their decisions in choosing to (or not to) apply to graduate school at all.

The current study is an extension of our admissions research conducted from a multistakeholder perspective. We compare how upper-division undergraduate physics majors interested in graduate school rate the importance of various graduate admissions criteria to a successful application; previously, we discussed these criteria $[3,4]$ from the faculty perspective alone. This extended understanding is particularly important for faculty involved in mentoring students about graduate applications. Further, students may be able to make more informed decisions by understanding how faculty perspectives shape the admissions processes.

\section{THEORETICAL BACKGROUND}

In an educational setting, a "stakeholder" is an individual or a collective entity that can affect, or is affected by, the welfare and success of the institution. Thus, for a school context, stakeholders can be teachers, students, school administrators, advisors, parents, and the government. A multistakeholder perspective encourages institutions to be sensitive to every stakeholder's contributions, concerns, 
ideas, and reasoning in their decision making [8]. As an example, a commonly used practice in physics education is to develop and test a new intervention in a reformed classroom. It is typical that the faculty are perceived as critical stakeholders; yet in addition, students' experiences of that intervention are clearly an important input and are often made central in assessing the interventions. Students hold valid perspectives based on their experiences, thus, should be treated as important stakeholders.

Another consideration is that students' experiences are influenced by their cultural capital which is literally students' inherited knowledge. Typical examples of such cultural capitals are students' embodied knowledge about themselves, or about the groups they identify to fit in, or contexts or expectations about faculty or peer support, etc., [9]. Therefore, understanding how such considerations shape students' experiences will lead to a greater understanding of the efficacy of the intervention and, in turn, will benefit improving the intervention appropriately.

Individuals make decisions based on their perception of a situation, the expected outcomes of a choice $[10,11]$, and individuals' self-beliefs [12], rather than making decisions based on what an "independent observer" might identify [13]. Therefore, in studies of choice action, i.e., decision making, perceptions are central.

In the context of admissions, stakeholders' varied perceptions associated with admissions will influence their admissions-related decisions. For example, the perception of "engineering as a highly analytic discipline and requires hard work" was reported as an admissions barrier in engineering [14]. Another germane example is that students may spend significant time and energy to satisfy the perceived importance of certain admissions criteria which, if not seen "similarly" by faculty, may be exhaustive for students without leading to success. So, in the current study, students' perceptions of application reviews (and associated outcomes) are a form of cultural capital, and institutions could use such knowledge to better understand the admissions landscape.

\section{A. Research question}

Given the above context, we note that one's perceptions of admissions provides a framework for decision making related to graduate applications. Understanding graduate admissions through the views of multiple stakeholders can better inform everyone about admissions-related practices. Past work has successfully studied students' perceptions in various contexts, including academic advising [15], preparedness for higher education [16], undergraduate research experiences, and college selection [17], yet little is known about students' graduate admissions-related perceptions. Thus, we set out to examine how physics undergraduates perceive the importance of various graduate admission criteria in the application process. Our specific research question is as follows:
- How do the ratings of the importance of various admission criteria compare for two stakeholder groups-prospective students and faculty?

\section{SURVEY DEVELOPMENT AND DATA COLLECTION}

\section{A. Survey development}

In coordination with other research activities of the APS Bridge Program, we developed a survey [the Post Graduation Career Intentions survey (PGCI)] to gather information on undergraduate students' motivation, perceived barriers, interests, graduate career goals, and current understanding of the graduate application or admissions process. The PGCI survey involves 27 multipart questions, that included both anchored scale-type items and openended response items. A pilot version of this instrument was developed by us in the summer of 2016 based on prior work in this area $[3,4]$ and primarily using items that had been previously developed and validated for similar populations. The survey questions were discussed within the APS Bridge Program team and with DBER colleagues at FIU. Based on this feedback, revisions were made to the pilot version. We then assessed the construct and content validity by testing the revised version on 14 undergraduate physics majors at FIU during the fall of 2016. Students' feedback was collected through a focus group and suggestions were incorporated into the final version. The final survey appears as Supplemental Material [18] to this article.

The final version of the PGCI survey was administered in conjunction with the American Institute of Physics (AIP) annual data collection from upper-division physics majors. Students responding to the annual AIP survey were asked to subsequently take the PGCI survey if they were willing to answer further questions. The PGCI survey was available from December 2016 until February 2017 online through a secure link. AIP also sent email reminders to nonrespondents to increase the survey participation rate.

\section{B. PGCI survey response and demographics}

A total of 1031 students responded to the PGCI. The response rate is at least $14 \%$ (calculated from the initial list of approximately 7250 nonduplicated email addresses; however, it was not possible to precheck the validity of all of these addresses, so the true response rate is somewhat higher). In the survey, we gathered information about whether students were interested in applying to graduate school (either master's or Ph.D.) in physics. Approximately $79 \%$ ( $N=816$ of 1031 respondents) exhibited some level of interest in applying to graduate school. As juniors and seniors were the population of interest, we included only such participants in our analysis, $N=802$.

In this article, we are interested in the responses of students to one multipart question in the PGCI survey about 
the importance of various admission criteria for application success, and further comparing it to similar, earlier responses of another stakeholder group (admissions-related faculty).

In this analysis, respondents' gender and race or ethnic identity are not directly part of the analysis, though we report the overall gender and race or ethnic demographics to indicate the representativeness of our sample. In our data, $23 \%$ of respondents identified themselves as female. A total of $12 \%$ of the sample self-identified as Hispanic, Latino, or Spanish origin, and 4\% identified as Black or African American (note that respondents were able to identify any and all of their racial or ethnic and gender identities, so these groups are not mutually exclusive). These proportions are fairly reflective of the college-age population of these groups as well as the proportion of degrees awarded in physics in recent years $[19,20]$.

\section{PGCI survey analysis and comparison of responses}

The PGCI survey question analyzed in this article is as follows:

- How important do you think the following criteria are for a successful graduate school application?

This question included 14 admission criteria, each rated independently on a 7-point, anchored scale running from "least important" to "most important." The criteria were as follows:

1. GPA or grades, general

2. GPA or grades, physics or math

3. Undergraduate courses taken

4. Undergraduate institution type or reputation

5. GRE quantitative scores

6. GRE verbal scores

7. GRE written scores

8. GRE physics subject scores

9. Letters of recommendation

10. Reputation of recommenders

11. Proximity or familiarity to the department

12. Personal statement

13. Prior research experiences (including conference participation)

14. Prior research publications

We analyzed students' responses to the above question by comparison with previous faculty responses to the same. So, we matched student responses to faculty responses for the exact same criteria collected through another surveythe graduate admissions survey (GAS) discussed in previous work [3]. The survey question in the faculty survey (GAS) was worded as "Please indicate the importance of each of the following factors to your admission decisions, if they are currently used."

This latter group of faculty was recruited through their connection to admissions at doctoral degree-granting physics departments in the U.S.A total of 170 faculty, who identified themselves from being from $149 \mathrm{Ph}$.D.-granting departments (amongst 185 solicited departments) responded to the graduate admission survey. The response rate of the graduate admissions survey for faculty was $75 \%$, representing a broad spectrum of Ph.D.-granting departments in the country.

In earlier work, we reported weighted mean responses of each criteria in order to balance multiple faculty responses from a single institution. In addition, faculty were provided with an additional response option of "don't use" for every criterion. Those faculty who identified that they don't use any particular criterion were eliminated in the means reported below. In the PGCI survey, we report the unweighted mean responses so that each student respondent weighs equally.

\section{Comparison of stakeholders' responses}

We compared the mean responses for each admission criterion amongst the two stakeholder groups. The statistical significance of the difference of each pair of responses (e.g., comparing between stakeholder groups) was determined using a series of Wilcox rank sum tests. Further, we computed effect sizes for all criteria that were found to be significantly different (at the $p<0.01$ level). We use Cliff's delta (d) as the estimate of effect size for such ordinal data. Historically, an effect size between 0.1 and 0.3 is categorized as "small," between 0.3 and 0.5 as "medium," and between 0.5 and 0.7 as "large" [21]. All elements of the analysis were performed in $R$ [22].

\section{DATA ANALYSIS}

Figure 1 shows the mean responses (along with the standard errors) of 14 admission criteria for the two stakeholder groups.

As shown in the graph, a total of 12 out of 14 admission criteria are rated higher, on average, than the midpoint of the scale (4), indicating that both stakeholder groups consider many criteria as simultaneously important for a successful graduate school application. Table I lists the mean and standard errors for the 5 highest rated criteria for each stakeholder group.

As shown in Table I, the top 3 criteria from students' perspectives-letters of recommendation, prior research experiences, and GPA or grades in physics or math courses-are also listed amongst the top 5 important in the faculty group. Specifically, letters of recommendation are rated as the most important for students, and the second most important for faculty. Similarly, the importance of physics or math GPAs is not surprising. A strong similar response about the top criteria between multistakeholders' views suggests that there is some shared cultural values or messages amongst these communities.

The general trend of considering multiple criteria as simultaneously important, i.e., important at the same time, is common to both the stakeholder groups, but there are notable differences between them. Table II shows the 


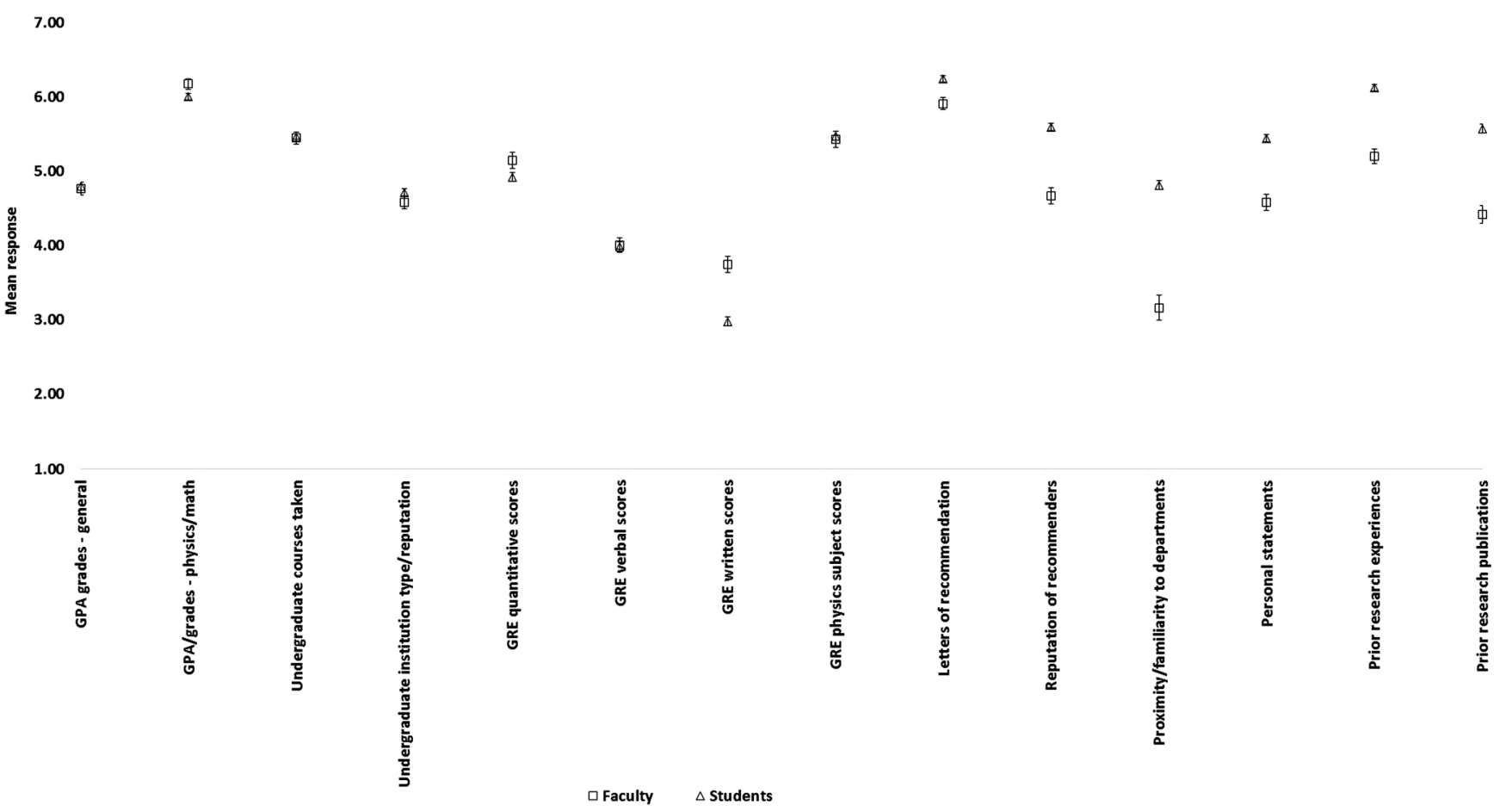

FIG. 1. Mean response of 14 admission criteria ranking of student $(N=802)$ and admission-associated faculty $(N=149)$ groups.

admission criteria that were ranked significantly differently between the two groups. The effect size is reported for each. For ease, we list these criteria in descending order of importance according to students' ranking.

As shown in Table II, a total of 5 out of the 14 admission criteria were ranked significantly different in importance. Interestingly, 3 of these admission criteria (prior research experience, the reputation of recommenders, and prior research publications) were ranked amongst the top 5 (most important) criteria by students. Thus, although the criteria are simultaneously considered important, certain criteria are perceived differently between groups. For example, both faculty and students perceived prior research experiences and prior research publications as highly

TABLE I. Mean response and standard errors for the top 5 high rated admission criteria. Bolded criteria are unique to each stakeholder group.

\begin{tabular}{lllllll}
\hline \hline & \multicolumn{2}{c}{ Stakeholder group I (students $N=802)$} & & & \multicolumn{2}{c}{ Stakeholder group II (faculty $N=149)$} \\
\cline { 2 - 3 } Criteria ranking & \multicolumn{2}{c}{ Admission criteria } & Mean \pm standard error & & Admission criteria & Mean \pm standard error \\
\cline { 2 - 3 } 1 & Letters of recommendation & $6.25 \pm 0.04$ & & GPA or grades, physics or math & $6.18 \pm 0.07$ \\
2 & Prior research experiences & $6.13 \pm 0.04$ & & Letters of recommendation & $5.92 \pm 0.08$ \\
3 & GPA or grades, physics or math & $6.01 \pm 0.04$ & & Undergraduate courses taken & $\mathbf{5 . 4 5} \pm \mathbf{0 . 0 8}$ \\
4 & Reputation of recommenders & $\mathbf{5 . 6 0} \pm \mathbf{0 . 0 5}$ & & GRE physics subject & $\mathbf{5 . 4 3} \pm \mathbf{0 . 1 1}$ \\
5 & Prior research publications & $\mathbf{5 . 5 8} \pm \mathbf{0 . 0 6}$ & & Prior research experiences & $5.20 \pm 0.10$ \\
\hline \hline
\end{tabular}

TABLE II. Mean response and standard errors of significantly different admission criteria. (Note that $* *$ : $p<0.001)$.

\begin{tabular}{lcc}
\hline \hline & $\begin{array}{c}\text { (Stakeholder Group I: } \\
\text { Students, } N=802) \\
\text { Admission criteria }\end{array}$ & $\begin{array}{c}\text { (Stakeholder group II: } \\
\text { Faculty, } N=149) \\
\text { Mean } \pm \text { standard error }\end{array}$ \\
\hline Prior research experiences & $6.13 \pm 0.04^{* *}(d=0.41)$ & $5.20 \pm 0.10$ \\
Reputation of recommenders & $5.60 \pm 0.05^{* *}(d=0.39)$ & $4.68 \pm 0.11$ \\
Prior research publications & $5.58 \pm 0.06^{* *}(d=0.42)$ & $4.42 \pm 0.12$ \\
Personal statements & $5.45 \pm 0.05^{* *}(d=0.34)$ & $4.58 \pm 0.11$ \\
Familiarity with department & $4.82 \pm 0.06^{* *}(d=0.52)$ & $3.17 \pm 0.07$ \\
\hline \hline
\end{tabular}


important, although students' ranking suggests their tendency to consider it far more important than faculty.

\section{DISCUSSION AND CONCLUSIONS}

Directly studying students' perceptions about admissions is certainly a more effective way of understanding choice actions than simply waiting for the outcome of students' decision making, leaving departments in the unenviable position of having to interpret and process applicant pools without this knowledge. Our approach of comparing student and faculty perceptions allows for the opportunity to learn more about each of these stakeholder groups.

The undifferentiated importance of recommendation letters as perceived by both faculty and students suggests that they play a critical part in the graduate school application process. We note, however, that in rating any of these criteria as "important", we do not have information for the context or meaning attached. Specifically, we highlight a need for students, letter writers, and admissions faculty alike to be aware of issues of implicit bias and similar effects that may be most salient in letters of recommendation [23,24]. Though both stakeholder groups rank letters as important but this does not eliminate the significant potential risks (to diversification in particular) posed by these factors in admissions.

Another opportunity for students to discuss their interests and motivations for graduate research (which have been found to significantly predict career scientific productivity $[25,26]$ ) as well as personal challenges or obstacles that have been overcome is found in personal statements. Thus, the finding that students place a relatively high importance on this factor is consistent. However, the rating from faculty is significantly lower. Thus, the risk here is that faculty may not be investing as much time reading or placing as much weight on personal statements, which may lead to some students being evaluated incompletely. Further, if faculty are not placing sufficient importance on considering student motivations, they risk missing out on a critical factor for scientific success. Thus, we see again that from the multi-stakeholder framing, including the perspectives of multiple groups is critical for improving the effectiveness of institutional decision making.

The multistakeholder perspective applied in this study provides an important contribution to understanding the graduate admissions landscape. Students hold significant influence over admissions, albeit in a way that may be invisible to graduate departments: students make many important choices about graduate school before admissions committees ever see their applications, even though they may not get considered as stakeholders and their perceptions about admissions may be unaccounted for informing institutional decision making. To the authors' knowledge, PGCI is the first nationally representative survey that collected undergraduate students' perceptions about graduate physics education and admissions. This analysis treated prospective students' perceptions as authentic and valid views on the admissions process alongside faculty and, by combining these views of the importance of various admission criteria, allows for a better understanding of the graduate landscape.

\section{ACKNOWLEDGMENTS}

This material is based upon work supported by the National Science Foundation under Grant No. 1143070.
[1] T. Hodapp and E. Brown, Making physics more inclusive, Nature (London) 557, 629 (2018).

[2] K. G. Stassun, A. Burger, and S. E. Lange, The FiskVanderbilt masters-to-Ph.D. bridge program: A model for broadening participation of underrepresented groups in the physical sciences through effective partnerships with minority-serving institutions, J. Geosci. Educ. 58, 135 (2010).

[3] G. Potvin, D. Chari, and T. Hodapp, Investigating approaches to diversity in a national survey of physics doctoral degree programs: The graduate admissions landscape, Phys. Rev. Phys. Educ. Res. 13, 020142 (2017).

[4] D. Chari and G. Potvin, Admissions practices in terminal master's degree-granting physics departments: A comparative analysis, Phys. Rev. Phys. Educ. Res. 15, 010104 (2019).
[5] R. E. Scherr, M. Plisch, K. E. Gray, G. Potvin, and T. Hodapp, Fixed and growth mindsets in physics graduate admissions, Phys. Rev. Phys. Educ. Res. 13, 020133 (2017).

[6] T. Hodapp and K. Sparks Woodle, A bridge between undergraduate and doctoral degrees, Phys. Today 70, 50 (2017).

[7] D. Chari and G. Potvin, Becoming cultural navigators in a graduate physics community, APS Forum Educ. Newsletter (2018).

[8] R. E. Freeman, The Stakeholder Approach Revisited (Pitman, Boston, 1984).

[9] S. Clegg, Cultural capital and agency: connecting critique and curriculum in higher education, Br. J. Sociol. Educ. 32, 93 (2011).

[10] A. Bandura, Social Foundations of Thought and Action: A Social Cognitive Theory (Prentice Hall, Englewood Cliffs, NJ, 1986). 
[11] A. Wigfield and J. S. Eccles, The development of achievement task values: A theoretical analysis, Developmental Review 12, 265 (1992).

[12] A. Godwin, G. Potvin, Z. Hazari, and R. Lock, Identity, critical agency, and engineering: An affective model for predicting engineering as a career choice, J. Eng. Educ. 105, 312 (2016).

[13] M. L. De La Rosa, Is opportunity knocking?: Low-income students' perceptions of college, and financial aid, Am. Behav. Sci. 49, 1670 (2006).

[14] J. Tudor, R. Penlington, and L. McDowell, Perceptions and their influences on approaches to learning, Eng. Educ. 5, 69 (2010).

[15] J. S. Smith, First-year student perceptions of academic advisement: A qualitative study and reality check, NACADA J. 22, 39 (2002)

[16] E. Jansen and J. van der Meer, Ready for university? A cross-national study of students' perceived preparedness for university, Aust. Educ. Res. 39, 1 (2012).

[17] K. Absher and G. Crawford, Marketing the community college starts with understanding students' perspectives, Community Coll. Rev. 23, 59 (1996).

[18] See Supplemental Material at http://link.aps.org/ supplemental/10.1103/PhysRevPhysEducRes.15.023101 for post graduate career intentions (PGCI) survey.
[19] U.S. Census Bureau, Current population survey annual social and economic supplement (U.S. Census Bureau, Washington, DC, 2013 (Released March 2016).

[20] IPEDS, Degrees Earned by Underrepresented Minorities in Physics, American Physical Society (www.aps.org/ programs/education/statistics) (2018).

[21] J. Cohen, Power Analysis for the Behavioral Sciences, 2nd ed. (Lawrence Erlbaum, Hillsdale, NJ, 1988).

[22] R. development core Team, $R$ : A Language and Environment for Statistical Computing ( $\mathrm{R}$ Foundation for Statistical Computing, Vienna, Austria, 2017).

[23] K. Dutt, D. L. Pfaff, A. F. Bernstein, J. S. Dillard, and C. J. Block, Gender differences in recommendation letters for postdoctoral fellowships in geoscience, Nat. Geosci. 9, 805 (2016).

[24] J. Posselt, Toward inclusive excellence in graduate education: Constructing merit and diversity in $\mathrm{PhD}$ admissions, Am. J. Educ. 120, 481 (2014).

[25] Z. Hazari, G. Potvin, R. H. Tai, and J. T. Almarode, Motivation toward a graduate career in the physical sciences: Gender differences and the impact on science career productivity, J. Coll. Sci. Teach. 41, 90 (2012).

[26] Z. Hazari, G. Potvin, R. H. Tai, and J. Almarode, For the love of learning science: Connecting learning orientation and career productivity in physics and chemistry, Phys. Rev. ST Phys. Educ. Res. 6, 010107 (2010). 